\title{
Thermal Conductivity and Elastic Modulus Evolution of Thermal Barrier Coatings Under High Heat Flux Conditions
}

Dongming Zhu

Ohio Aerospace Institute, Cleveland, Ohio

Robert A. Miller

Glenn Research Center, Cleveland, Ohio

National Aeronautics and

Space Administration

Glenn Research Center 


\section{Acknowledgments}

The authors are grateful to George W. Leissler of Dynacs Engineering Company, Inc., Lewis Group for his assistance in the preparation of the thermal barrier coatings.

This report is a formal draft or working paper, intended to solicit comments and ideas from a technical peer group.

This report contains preliminary findings, subject to revision as analysis proceeds.

Available from

NASA Center for Aerospace Information

7121 Standard Drive

Hanover, MD 21076

Price Code: A00
National Technical Information Service 5285 Port Royal Road Springfield, VA 22100

Price Code: A00 


\title{
THERMAL CONDUCTIVITY AND ELASTIC MODULUS EVOLUTION OF THERMAL BARRIER COATINGS UNDER HIGH HEAT FLUX CONDITIONS
}

\author{
Dongming $\mathrm{Zhu}^{\dagger}$ and Robert A. Miller
}

National Aeronautics and Space Administration

Glenn Research Center, Cleveland, $\mathrm{OH} 44135$

\begin{abstract}
Laser high heat flux test approaches have been established to obtain critical properties of ceramic thermal barrier coatings (TBCs) under near-realistic temperature and thermal gradients that may be encountered in advanced engine systems. Thermal conductivity change kinetics of a thin ceramic coating were continuously monitored in real time at various test temperatures. A significant thermal conductivity increase was observed during the laser simulated engine heat flux tests. For a $0.25 \mathrm{~mm}$ thick $\mathrm{ZrO}_{2}-8 \% \mathrm{Y}_{2} \mathrm{O}_{3}$ coating system, the overall thermal conductivity increased from the initial value of $1.0 \mathrm{~W} / \mathrm{m}-\mathrm{K}$ to $1.15 \mathrm{~W} / \mathrm{m}-\mathrm{K}, 1.19 \mathrm{~W} / \mathrm{m}-\mathrm{K}$ and $1.5 \mathrm{~W} / \mathrm{m}-\mathrm{K}$ after 30 hour testing at surface temperatures of $990^{\circ} \mathrm{C}, 1100$; and $1320^{\circ} \mathrm{C}$, respectively. Hardness and modulus gradients across a $1.5 \mathrm{~mm}$ thick TBC system were also determined as a function of laser testing time using the laser sintering/creep and micro-indentation techniques. The coating Knoop hardness values increased from the initial hardness value of $4 \mathrm{GPa}$ to $5 \mathrm{GPa}$ near the ceramic/bond coat interface, and to $7.5 \mathrm{GPa}$ at the ceramic coating surface after 120 hour testing. The ceramic surface modulus increased from an initial value of about $70 \mathrm{GPa}$ to a final value of $125 \mathrm{GPa}$. The increase in thermal conductivity and the evolution of significant hardness and modulus gradients in the TBC systems are attributed to sintering-induced micro-porosity gradients under the laserimposed high thermal gradient conditions. The test techniques provide a viable means for obtaining coating data for use in design, development, stress modeling, and life prediction for various thermal barrier coating applications.
\end{abstract}

\section{INTRODUCTION}

Ceramic thermal barrier coatings (TBCs) are being developed for advanced gas turbine engine components to improve engine efficiency and reliability. However, the durability of the coating systems remains a crucial issue under the conditions of increased operating temperature

$\dagger$ Ohio Aerospace Institule, NASA Glenn Research Center. E-mail: Dongming.Zhu@grc.nasa.gov 
and extended hot exposure time that will be encountered in next generation engines. In particular, changes in thermomechanical and thermophysical properties as a result of coating sintering, such as the increase in coating elastic modulus and thermal conductivity, have become of a major focal point in the development of advanced thermal barrier coatings. Temperature-dependent change kinetics of the coating thermal conductivity and elastic modulus are among the most important parameters required for coating design and life prediction. Therefore, determination of thermal conductivity and elastic modulus evolution of thermal barrier coatings under near-realistic engine temperature and thermal gradients is of great importance.

In this paper, a laser steady-state heat flux technique is established to monitor overall thermal conductivity of ceramic coatings under simulated engine temperature and heat load conditions. Thermal conductivity change kinetics are thus determined for a plasma sprayed $\mathrm{ZrO}_{2}-$ $8 \mathrm{wt} \% \mathrm{Y}_{2} \mathrm{O}_{3}$ coating under a given laser heat flux and various surface temperature conditions. The elastic modulus evolution across a $\mathrm{ZrO}_{2}-8 \mathrm{wt} \% \mathrm{Y}_{2} \mathrm{O}_{3}$ ceramic coating is achieved by a laser pressure sintering and creep technique. The modulus change kinetics as a function of time and coating thickness are subsequently determined after the laser sintering experiments using the Knoop micro-indentation approach.

\section{EXPERIMENTAL MATERIALS AND METHODS}

\subsection{Thermal Conductivity Change Kinetics by Laser Steady-State Heat Flux Technique}

A high power $\mathrm{CO}_{2}$ laser was used to investigate thermal conductivity change kinetics of the ceramic coating under steady-state heating conditions. Figure 1 (a) shows a schematic diagram of the laser test rig. This rig consists of a $3.0 \mathrm{~kW} \mathrm{CO}$ continuous wave laser (wavelength $10.6 \mu \mathrm{m}$ ) (EVERLASE Vulcan, Coherent General Inc., Massachusetts), a motor driven rotating test station and temperature measurement instruments such as a thermograph system and pyrometers. The specimen configuration used for the thermal conductivity study was the $25.4 \mathrm{~mm}$ diameter, $3.2 \mathrm{~mm}$ thick CMSX-4 single crystal superalloy substrate, coated with a $0.12 \mathrm{~mm}$ low pressure plasma-sprayed (LPPS) Ni-36Cr-5Al-Y bond coat and a $0.25 \mathrm{~mm}$ air plasma-sprayed (APS) $\mathrm{ZrO}_{2}-8 \mathrm{wt} \% \mathrm{Y}_{2} \mathrm{O}_{3}$ ceramic coating. The specimen surface heating was provided by the laser beam, and the backside air cooling was used to maintain the desired specimen temperatures. A $12.5 \mathrm{~mm}$ thick aluminum plate with a $23.9 \mathrm{~mm}$ diameter center hole opening was used as an aperture to prevent the specimen from edge or side heating. A uniform laser power distribution was achieved over $23.9 \mathrm{~mm}$ diameter aperture region of the specimen (as confirmed by thermograph) by using an integrating $\mathrm{ZnSe}$ lens combined with the specimen rotation. Three 
platinum wire (wire diameter $0.38 \mathrm{~mm}$ ) flat coils were used to form an air gap between the aluminum aperture plate and the specimen to minimize the specimen heat losses through the plate.

During the thermal conductivity change kinetics testing, the ceramic surface temperature was measured by an $8 \mu \mathrm{m}$ infrared pyrometer (Model MX-M803 Maxline Infrared Thermometer Measurement and Control System, Ircon, Inc., Illinois). A side hole with diameter $1.06 \mathrm{~mm}$ (shown in Figure 1) was drilled through the center of the substrate by the electro-discharge machining (EDM) method, and the metal temperature at the mid point of substrate thickness near the center region was determined by an embedded type $K$ thermocouple ( $1 \mathrm{~mm}$ diameter Inconel alloy sheathed thermocouple, Omega Engineering, Inc., Connecticut). Using the reported thermal conductivity values of the CMSX-4 metal substrate [1] and a similar bond coat [2] shown in Figure 2, and the initial thermal conductivity $1.0 \mathrm{~W} / \mathrm{m}-\mathrm{K}$ for the $\mathrm{ZrO}_{2}-8 \mathrm{wt} \% \mathrm{Y}_{2} \mathrm{O}_{3}$ [3] , the interfacial temperatures, and thus the actual heat flux passing through the thermal barrier coating system, were determined under the steady-state laser heating conditions by one-dimensional (oneD) heat transfer models [4]. The radiation heat loss (total emissivity was taken as $0.50[5,6]$ ) and laser absorption corrections of the ceramic coating were considered in the calculations. Therefore, overall thermal conductivity changes were continuously monitored in real time during the test period by measuring the temperature difference across the ceramic coating. In the present study, three tests were carried out under the pass-through laser heat flux of $64 \mathrm{~W} / \mathrm{cm}^{2}$. During the tests, the ceramic surface temperatures were maintained at approximately at $990{ }^{\circ} \mathrm{C}, 1100{ }^{\circ} \mathrm{C}$ and $1320^{\circ} \mathrm{C}$, respectively. The total test time was up to 33 hours for a single test.

\subsection{Elastic Modulus Evolution under High Heat Flux Conditions}

The laser sintering and creep tests were carried out to induce elastic modulus changes in the porous and microcracked thermal barrier coating under high thermal gradients using a $1.5 \mathrm{~kW}$ $\mathrm{CO}_{2}$ laser (EVERLASE Arrow, Coherent General Inc., Massachusetts), as shown in Figure 1 (b). The detailed laser test conditions and procedures have been described elsewhere [7]. The specimen configuration used for the modulus study consisted of a $1.5 \mathrm{~mm}$ thick $\mathrm{ZrO}_{2}-8 \mathrm{wt}$. $\% \mathrm{Y}_{2} \mathrm{O}_{3}$ ceramic coating and a $0.25 \mathrm{~mm}$ thick Fe-25Cr-5Al-0.5Y bond coat, which were sprayed on the 4140 steel substrate (dimension $127 \times 32 \times 12.7 \mathrm{~mm}$ ). During the laser sintering test, the ceramic surface temperature was maintained at about $1080^{\circ} \mathrm{C}$ and the back side metal temperature at $100{ }^{\circ} \mathrm{C}$. The specimens were continuously heated for either 1 hour, 11 hours, 22 hours, and 120 hours. The ceramic creep strains were measured from the through-thickness, wedge-shape crack openings in the ceramic coating that were observed both on the coating surface and in the cross-sections by metallography after the laser sintering experiments. 

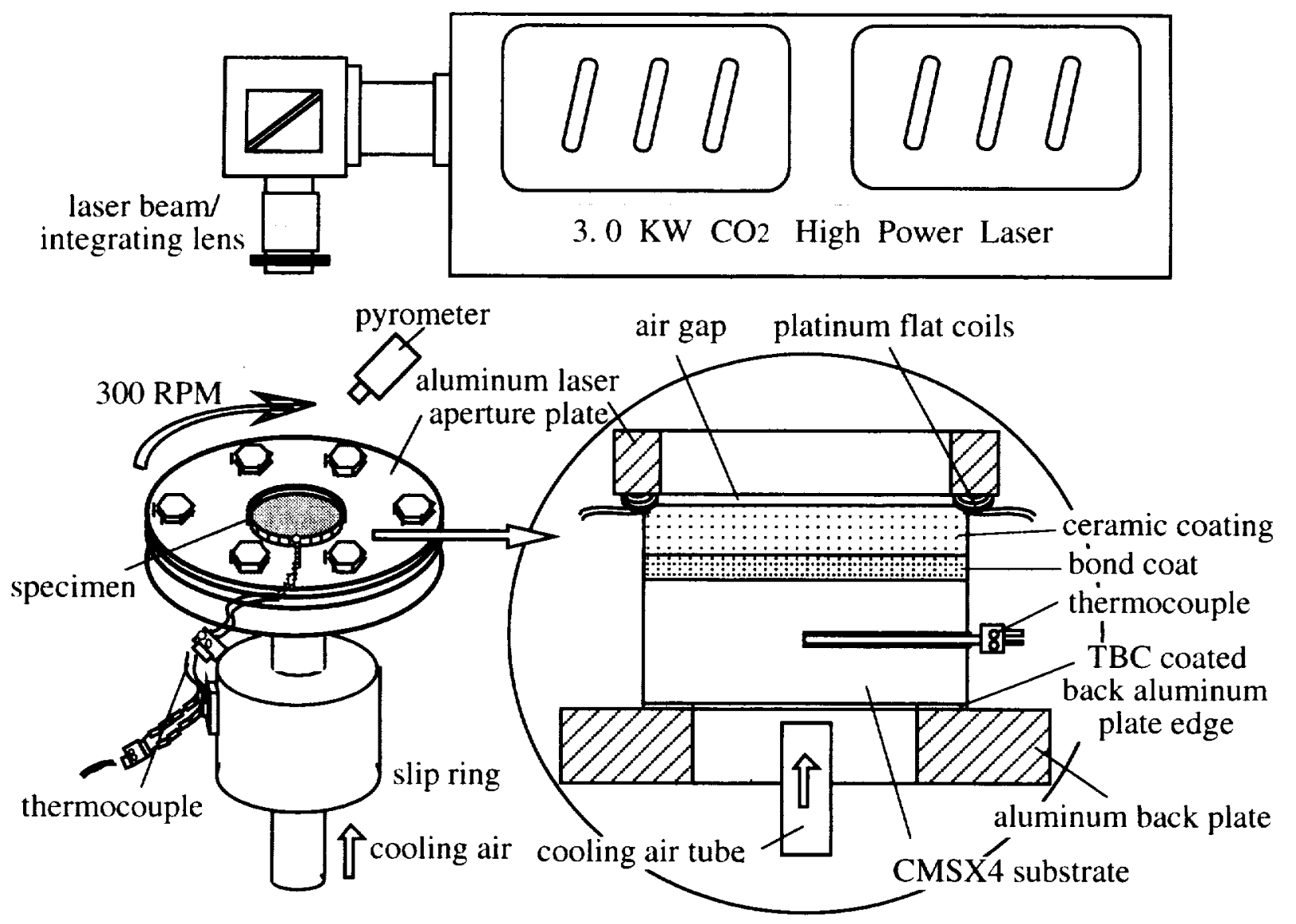

(a)

Fig. 1 Schematic diagrams of high power $\mathrm{CO}_{2}$ laser rigs for determining thermal conductivity change kinetics and elastic modulus evolution of the ceramic thermal barrier coatings under steady-state heat flux conditions. (a) Laser high heat flux technique for monitoring thermal conductivity change kinetics; (b) Laser sintering and creep technique for evaluating ceramic creep behavior and modulus evolution under thermal gradient conditions. 

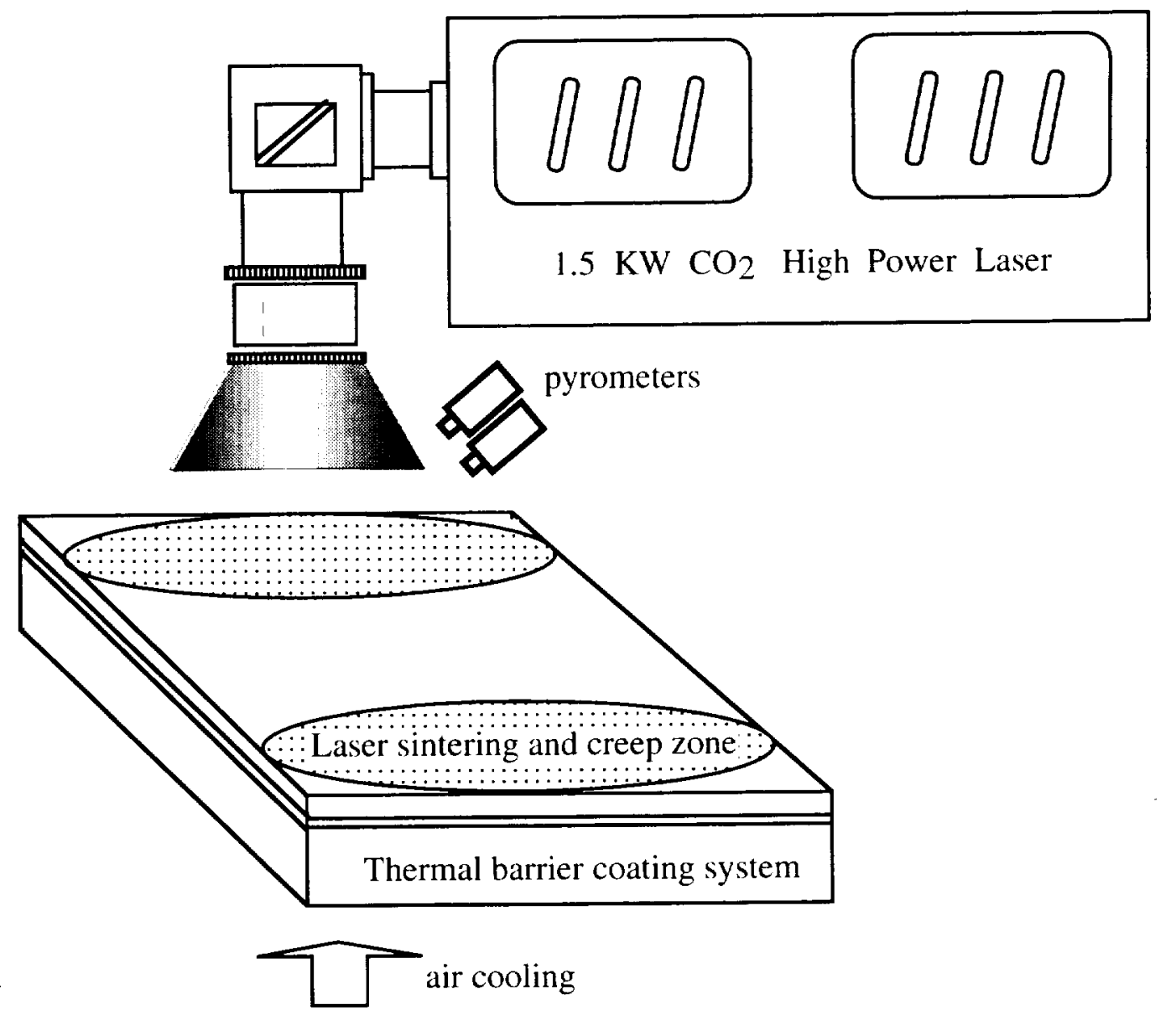

(b)

Fig. 1 (Continued) Schematic diagrams of high power $\mathrm{CO}_{2}$ laser rigs for determining thermal conductivity change kinetics and elastic modulus evolution of the ceramic thermal barrier coatings under steady-state heat flux conditions. (a) Laser high heat flux technique for monitoring thermal conductivity change kinetics; (b) Laser sintering and creep technique for evaluating ceramic creep behavior and modulus evolution under thermal gradient conditions.

The Knoop indentation method has been used to measure elastic modulus of bulk ceramics [8] and ceramic coatings $[9,10]$. By measuring elastic recovery of residual surface impression of the indentation long and short diagonals (with half lengths $a^{\prime}$ and $b^{\prime}$, respectively) and hardness $H$, the modulus $E$ can be estimated by

$$
E=\alpha \cdot\left(\frac{b}{a}-\frac{b^{\prime}}{a^{\prime}}\right)^{-1} \cdot H=\alpha \cdot\left(\frac{b}{a}-\frac{b^{\prime}}{a}\right)^{-1} \cdot H
$$


where $\alpha$ is a constant ( $\alpha=0.45$ ), $a$ and $b$ are the half lengths of the long and short diagonals before elastic recovery, and $b / a=1 / 7.11$ for a perfect indenter. In this study, the ceramic coating modulus distributions as a function of time were determined on the cross-sections of the coating system after the laser sintering tests using this Knoop indentation technique. The Knoop indentation tests were carried out on the polished cross-sections of laser sintered specimens using a microhardness tester (Micromet II, Buehler, Illinois), in accordance with ASME C1326. The load used was $500 \mathrm{~g}(4.9 \mathrm{~N})$ and dwell time was 15 seconds. At least eight column indentation sequences (more than 150 measurements) across the coating system were performed for each specimen.

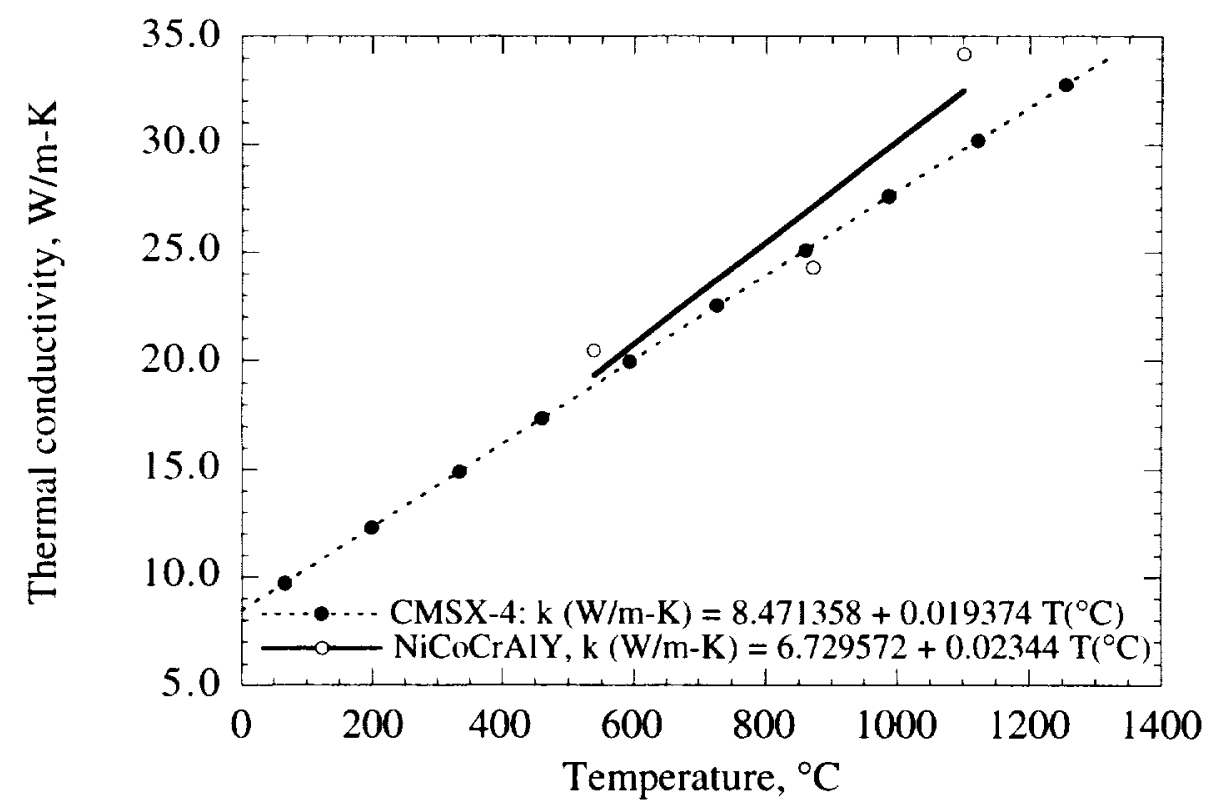

Fig. 2 Literature reported thermal conductivity values for the CMSX metal substrate and NiCoCrAlY bond coat.

\section{EXPERIMENTAL RESULTS AND DISCUSSION}

\subsection{Thermal Conductivity Change Kinetics}

Figure 3 shows typical temperature profiles of the $\mathrm{ZrO}_{2}-\mathrm{Y}_{2} \mathrm{O}_{3}$ thermal barrier coating system tested at a surface temperature of approximately $1320{ }^{\circ} \mathrm{C}$ during the laser thermal conductivity test. Under the constant steady-state laser high heat flux condition (heat flux 
approximately $64 \mathrm{~W} / \mathrm{cm}^{2}$ ), the measured ceramic surface temperature slightly decreased with time. On the other hand, the measured metal temperature increased with time. The temperature difference across the ceramic layer decreased from approximately $140{ }^{\circ} \mathrm{C}$ at the initial stage to $110^{\circ} \mathrm{C}$ after 33 hour testing, suggesting an overall thermal conductivity increase in the ceramic layer due to laser sintering. Note that a thermal conductivity gradient would be established across the ceramic coating (faster thermal conductivity increase near the ceramic surface as compared to near the ceramic/bond coat interface) under the high thermal gradient conditions. Therefore, the ceramic thermal conductivity increase in the coating determined by the steady-state laser heat flux approach will reflect an overall effect of the conductivity increase in the coating. Figure 4 shows that the overall thermal conductivity change kinetics of the thermal barrier coating determined by the real time laser heat flux testing. The thermal conductivity increased from the initial value of $1.0 \mathrm{~W} / \mathrm{m}-\mathrm{K}$ to $1.15 \mathrm{~W} / \mathrm{m}-\mathrm{K}, 1.19 \mathrm{~W} / \mathrm{m}-\mathrm{K}$ and $1.5 \mathrm{~W} / \mathrm{m}-\mathrm{K}$ after 30 hour testing at the surface temperatures of $990^{\circ} \mathrm{C}, 1100^{\circ} \mathrm{C}$, and $1320^{\circ} \mathrm{C}$, respectively. The thermal conductivity change kinetics also showed the distinct two-stage rate increase characteristics: a fast and changing rate conductivity increase at the initial "primary" stage, and a slower rate and nearly constant conductivity increase at the "steady-state" stage. The irreversible thermal conductivity increase was demonstrated in the $990^{\circ} \mathrm{C}$ test where a couple of temperature cycles were introduced. The interrupted tests by thermal cycling did not alter the general trend of the thermal conductivity change kinetics.

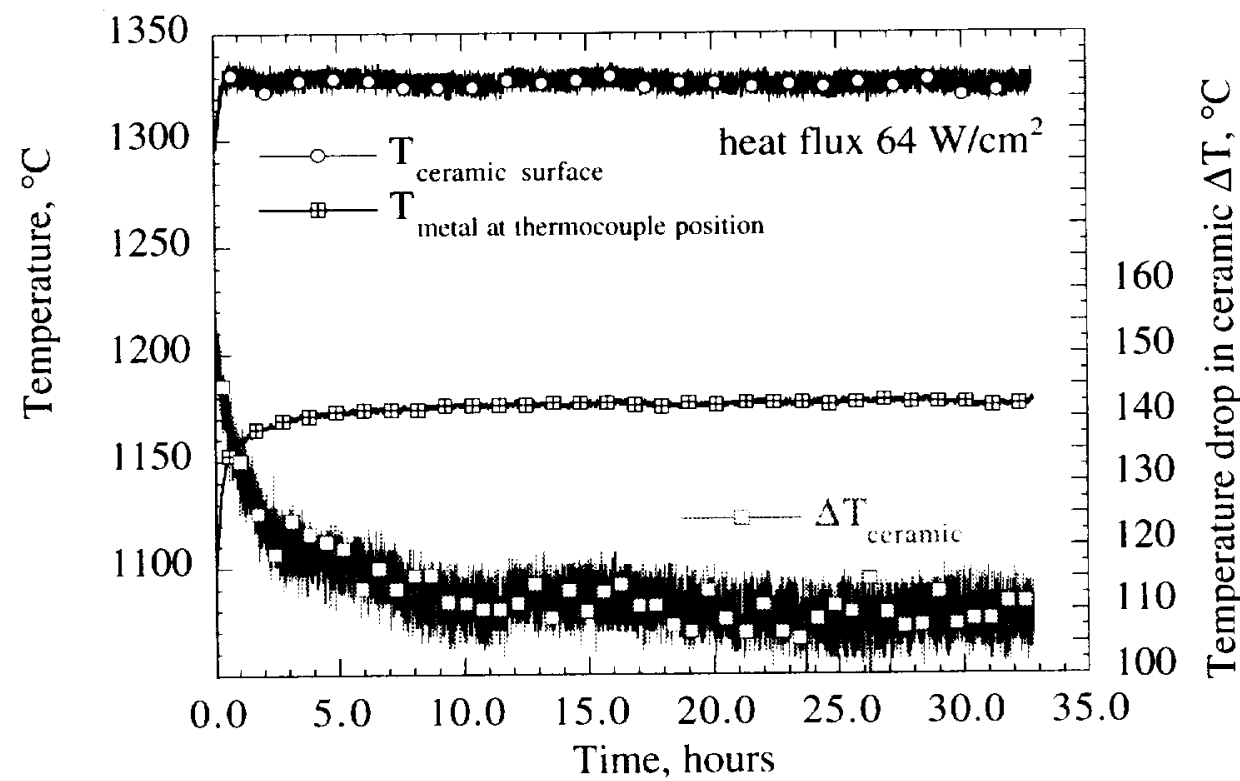

Fig. 3 Typical temperature profiles of the $\mathrm{ZrO}_{2}-\mathrm{Y}_{2} \mathrm{O}_{3}$ thermal barrier coating system tested at a surface temperature of approximately $1320^{\circ} \mathrm{C}$ during the laser thermal conductivity test. 


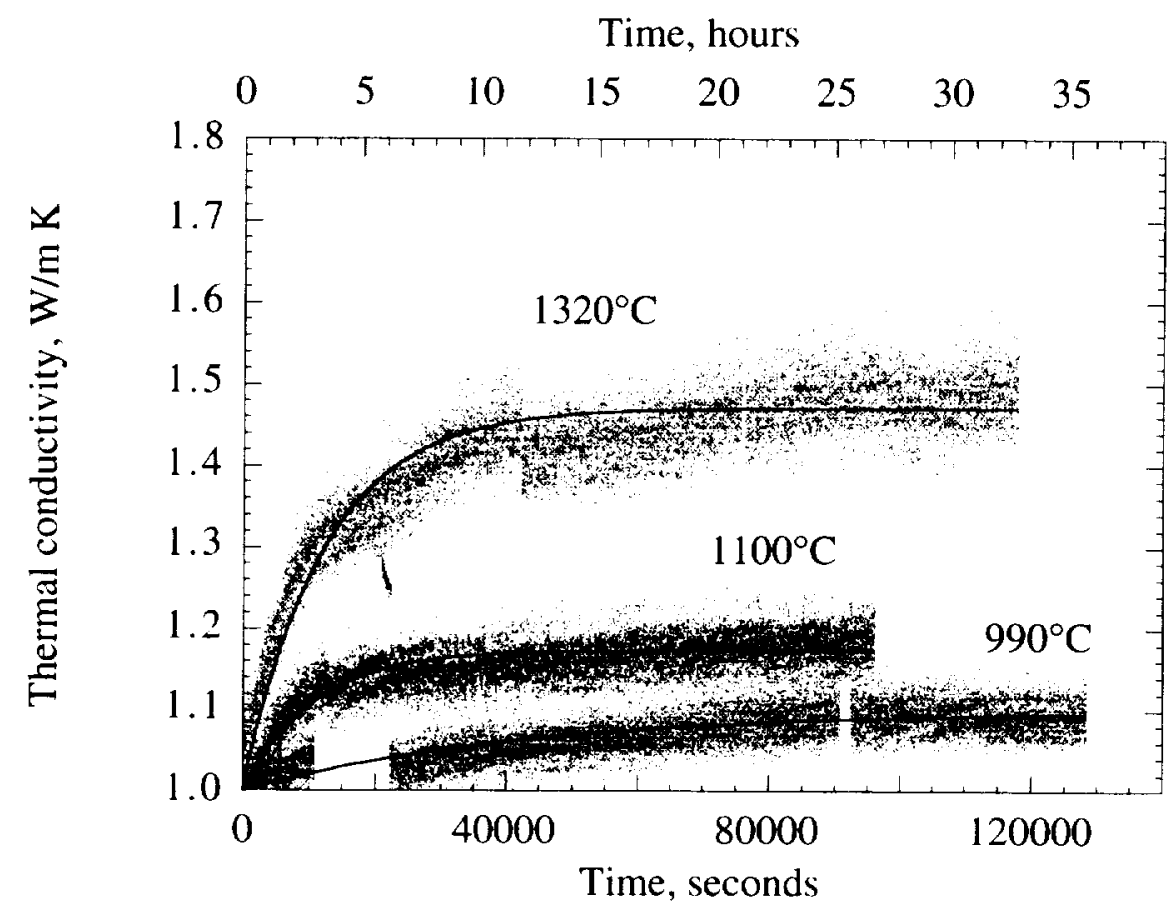

Fig. 4 The overall thermal conductivity change kinetics of the $\mathrm{ZrO}_{2}-\mathrm{Y}_{2} \mathrm{O}_{3}$ thermal barrier coating determined by the real time laser heat flux testing.

Figure 5 illustrates the ceramic thermal conductivity $\ln (\mathrm{k})$ as a function of Larson-Miller $\left(L-M\right.$ ) parameter ( $L-M=T[\ln (t)+C]$, where $t$ is the heating time in seconds and $T_{\text {ave }}$ is the average temperature in Kelvin in the ceramic coating, $\mathrm{C}$ is a fitting constant, and $\mathrm{C}=10$ in this study). The effects of heating time and temperature on the overall ceramic thermal conductivity are approximately described by the $\ln (\mathrm{k})$ vs. $L-M$ relationship. The average slope of the LarsonMiller plot for the $\mathrm{ZrO}_{2}-\mathrm{Y}_{2} \mathrm{O}_{3}$ coating was about $2.93 \times 10^{-5}$ for the thermal barrier coating system. The Larson-Miller slope obtained in this study is slightly higher than the slopes reported in literature $[11,12]$. This discrepancy may be attributed to a significantly fast conductivity increase at the primary stage for the coating observed in this study. Note that the Larson-Miller extrapolation approach for the thermal conductivity change kinetics cannot accurately describe the fast, variable conductivity increase rate at the initial primary stage. An approach is being established to characterize the ceramic thermal conductivity increase kinetics and the conductivity gradient effect under high heat flux conditions based on the visco-elastic relaxation theory [4] . 


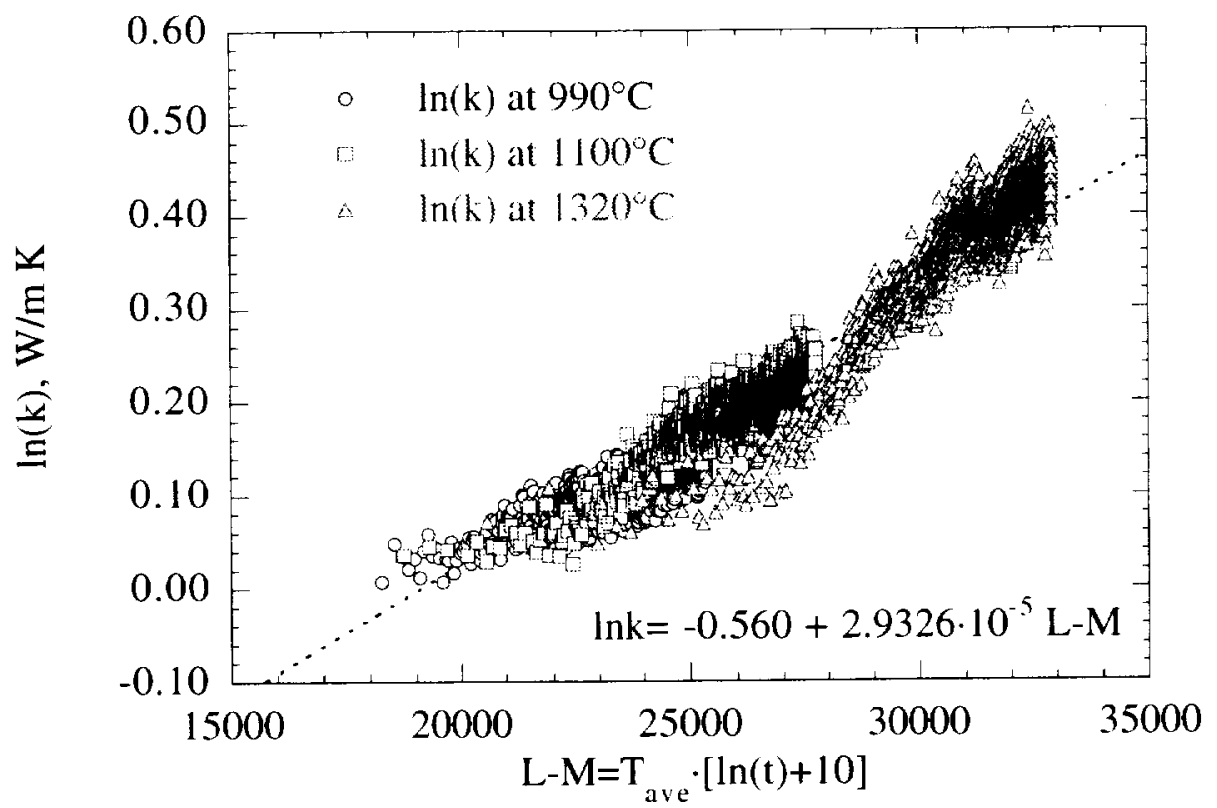

Fig. 5 Ceramic thermal conductivity $\ln (\mathrm{k})$ as a function of Larson-Miller $(L-M)$ parameter ( $L-M=T[\ln (t)+C]$, where $t$ is the heating time in seconds and $T$ is the absolute temperature in Kelvin, $\mathrm{C}$ is a constant). The effects of heating time and temperature on the overall ceramic thermal conductivity are approximately described by the conductivity - Larson-Miller relationship.

\subsection{The Elastic Modulus Evolution of the Ceramic Coating}

Figure 6 illustrates the micrographs of cross-sections of the thermal barrier coating and Knoop hardness indentations after an 11 hour laser sintering and creep test. Note that throughthickness, wedge-shape cracks were developed in the ceramic coatings as a result of the laser sintering. The micro-porosity was reported to decrease with increasing laser testing time, and the microcrack density observed in the ceramic coating near the surface region was much lower than that near the ceramic/bond coat interface region after the laser testing [4]. The porosity gradients across the coating thickness after laser testing were correlated to the measured total creep strain gradients shown in Figure 7 [4]. The morphology change in the ceramic coating is expected to result in coating hardness and modulus increases with laser testing time. 
Figure 8 illustrates Knoop hardness distributions in the $\mathrm{ZrO}_{2}-\mathrm{Y}_{2} \mathrm{O}_{3}$ thermal barrier coating system after laser sintering for various times. The hardnesses of the FeCrAlY and the steel substrate were approximately $2 \mathrm{GPa}-3 \mathrm{GPa}$, and essentially unaffected during the testing. The ceramic coating showed higher hardness values as compared to the bond coat and substrate. Note that the coating hardness increases after the laser testing. It can be seen that after 1 hour laser sintering, the increase in the coating hardness was relatively small, with coating hardness values in the range of $4 \mathrm{GPa}$ to $5 \mathrm{GPa}$, which were not much higher than the initial untested coating hardness value of about $4 \mathrm{GPa}$. However, after 11 hour laser sintering, the coating surface region had a significant increase in hardness (near surface hardness value of about 7.0 GPa), but the near ceramic/bond coat interface region remained almost unchanged. After 120 hour laser sintering, the entire ceramic coating had a more significant increase in hardness. The Knoop hardness values increased from the initial hardness value of $4 \mathrm{GPa}$ to $5 \mathrm{GPa}$ near the ceramic/bond coat interface, and to $7.5 \mathrm{GPa}$ at the ceramic coating surface.

Figure 9 shows the elastic modulus measurement results in the $\mathrm{ZrO}_{2}-\mathrm{Y}_{2} \mathrm{O}_{3}$ thermal barrier coating obtained by the indentation technique as a function of laser sintering time. The relatively large data scatter in the modulus values is a consequence of the porous and heterogeneous nature of the plasma-sprayed ceramic coating. Therefore, the experimental data have been smoothed using a fifth order polynomial. It can be seen that the ceramic modulus change followed a similar trend to the ceramic hardness change during the laser sintering process. The surface modulus increased from an initial value of about $70 \mathrm{GPa}$ to the final value of $125 \mathrm{GPa}$, after 120 hour testing. The experimentally determined modulus change kinetics across the coating system shown in Figure 10 can be well described by the visco-elastic behavior [7]

$$
\frac{E_{c}-E_{c}^{0}}{E_{c}^{\text {inf }}-E_{c}^{0}}=C_{E}\left\{1-\exp \left[-\frac{t}{\tau}\right]\right\}
$$

where $E_{c}$ is the coating modulus at any given time $\mathrm{t}, E_{c}^{0}$ and $E_{c}^{\mathrm{inf}}$ are ceramic coating modulus values at the initial time and at infinitely long time, respectively, $\tau$ is relaxation time, $C_{E}$ is a constant related to temperature and stress in the coating system. It can be seen that a modulus gradient was established in the coating system which evolved with time under the laser imposed temperature and stress gradients. The surface showed very fast modulus increase kinetics. The surface of the ceramic coating reached nearly the assumed final modulus value of $125 \mathrm{GPa}$ in about 20 hours. However, from the experimental observations, a much longer time is required for the inner layers of the ceramic coating to obtain the final modulus value by laser sintering due to the lower temperatures and stresses under the thermal gradient test conditions. 


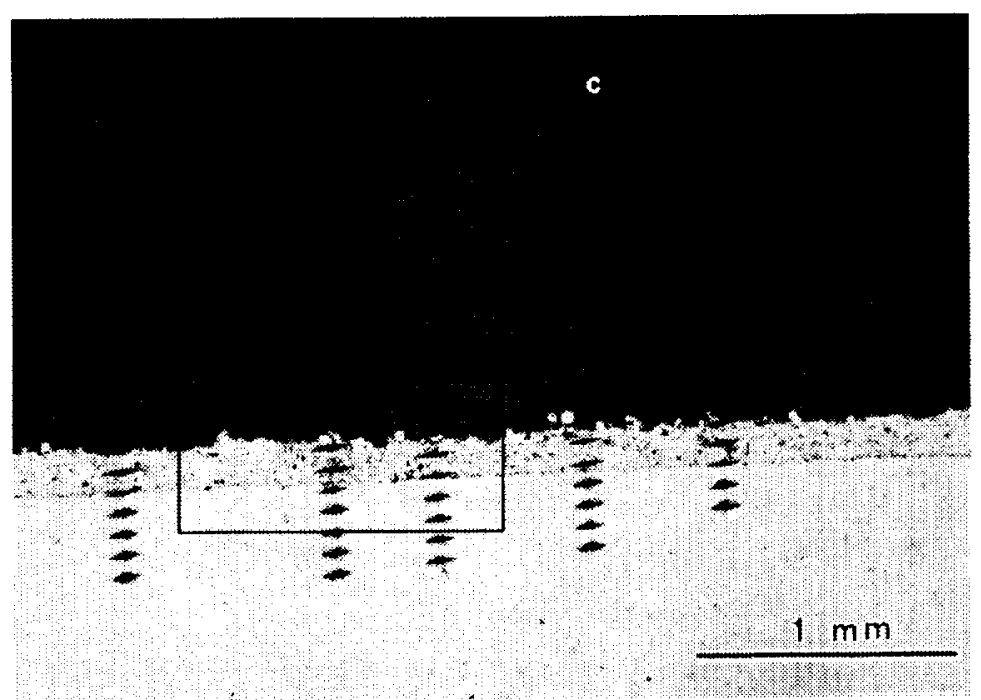

(a)

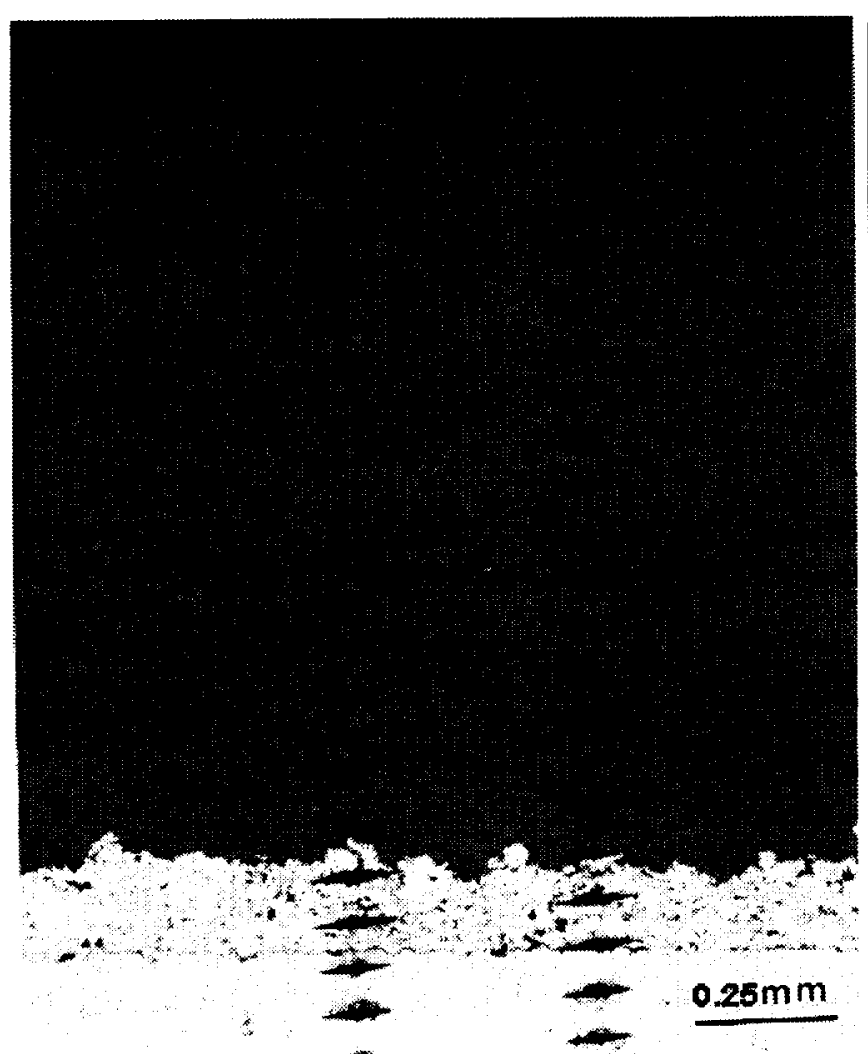

(b)

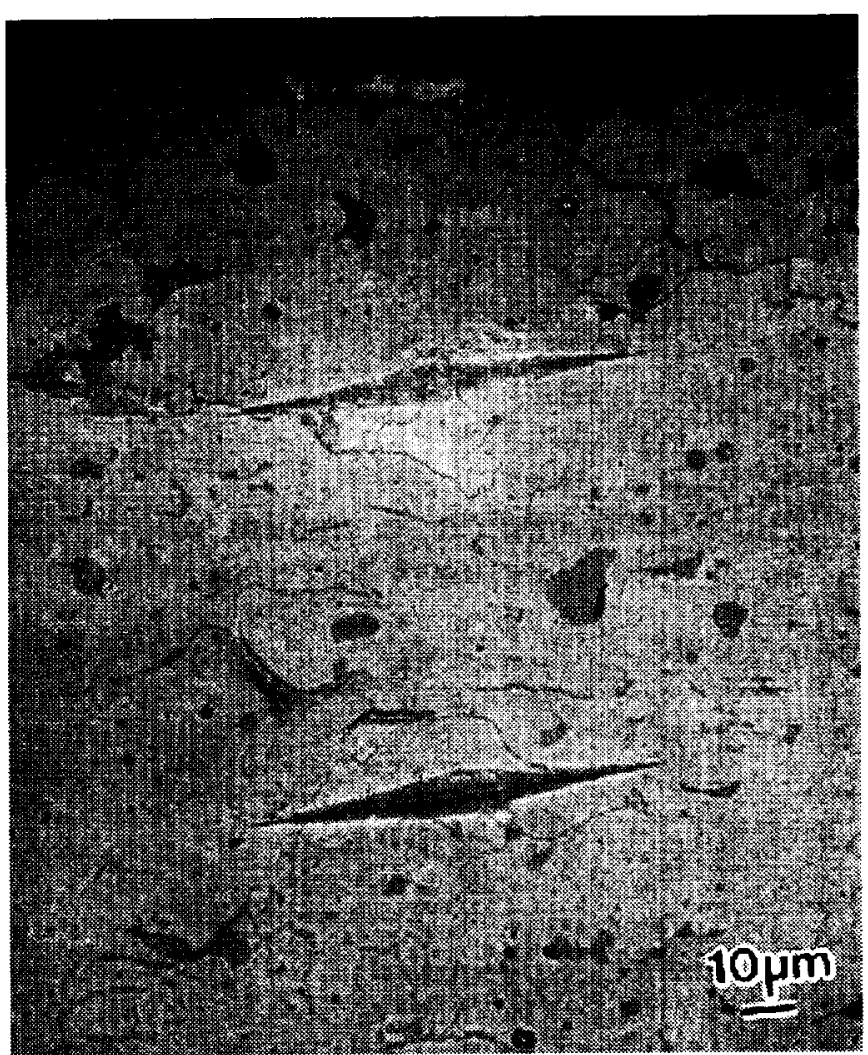

(c)

Fig. 6 Micrographs of cross-sections of the thermal barrier coating and Knoop hardness indentations after an 11 hour laser sintering and creep test (Fig. 6 (a), (b) and (c) show various magnifications of the coating system, respectively). 


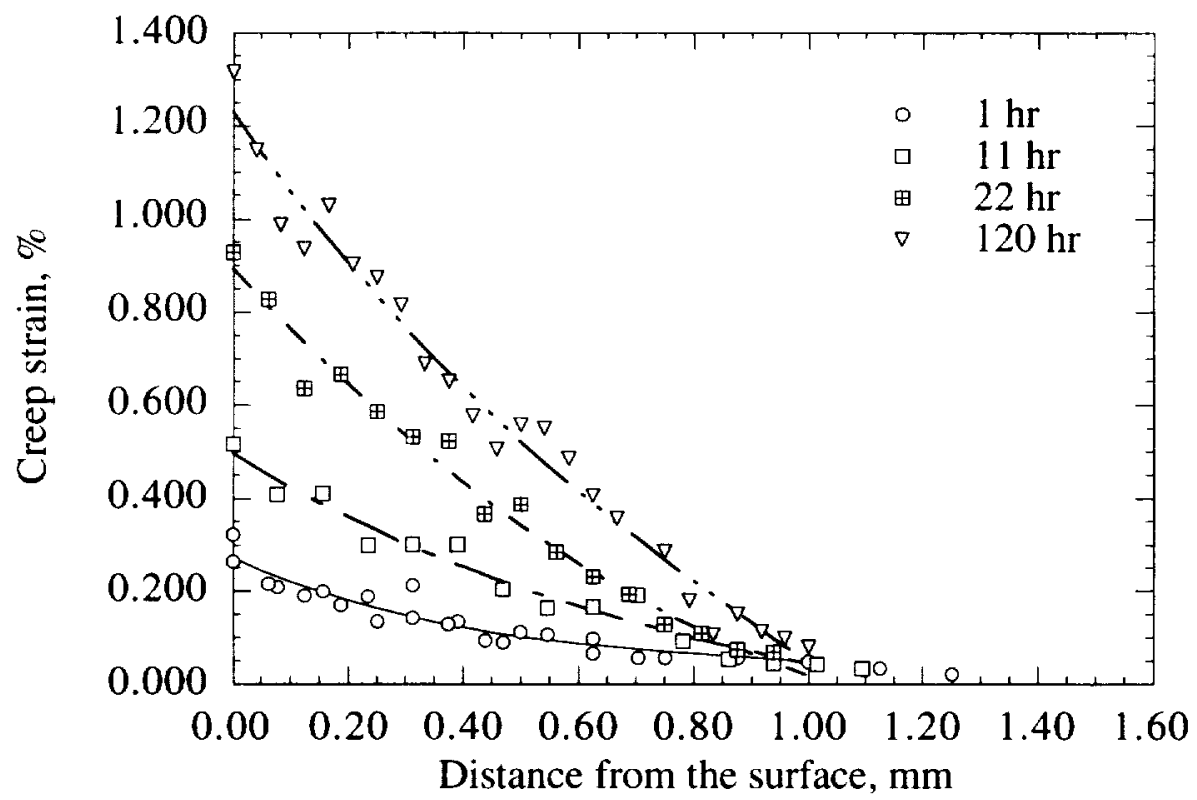

Fig. 7 The creep strain gradient resulting from laser imposed temperature and stress gradients as a function of laser testing time in a $\mathrm{ZrO}_{2}-\mathrm{Y}_{2} \mathrm{O}_{3}$ thermal barrier coating system. 


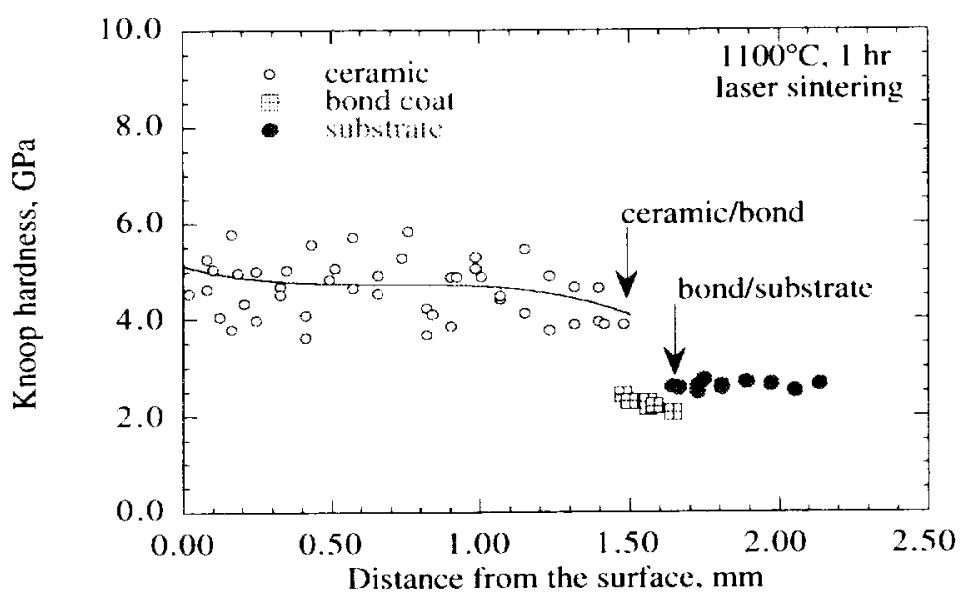

(a)

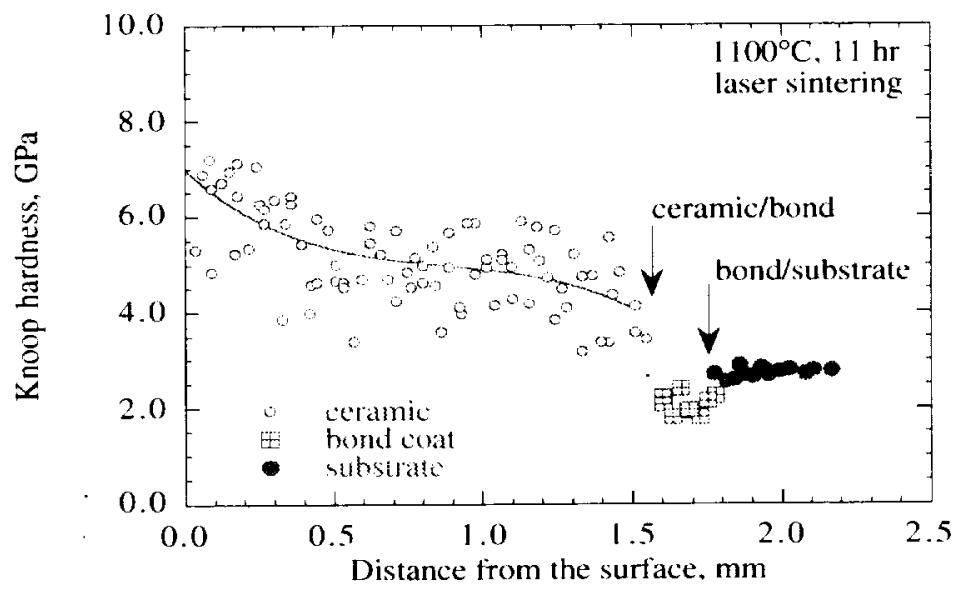

(b)

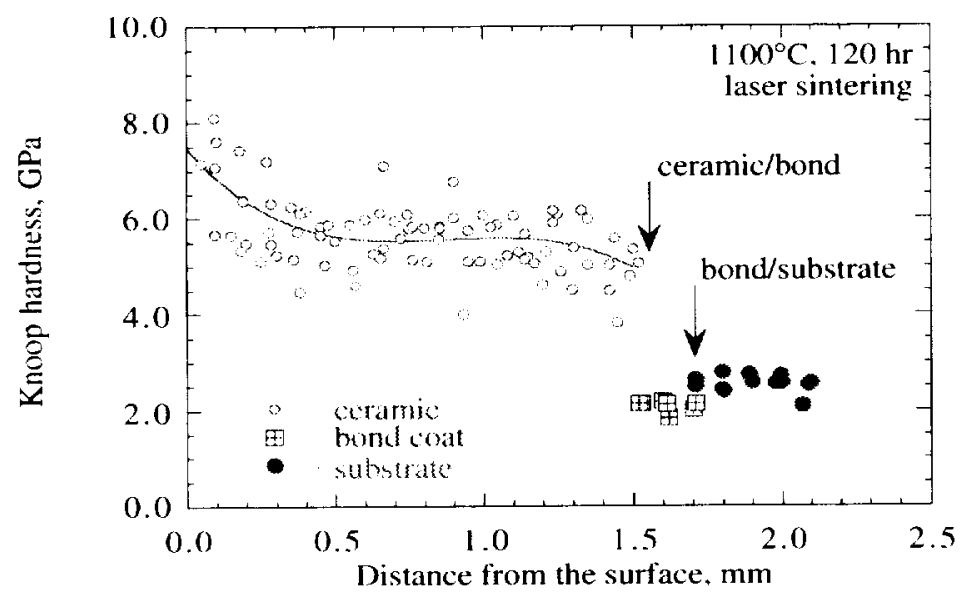

(c)

Fig. 8 (Continued) Knoop hardness distributions in a $\mathrm{ZrO}_{2}-\mathrm{Y}_{2} \mathrm{O}_{3}$ thermal barrier coating system after laser sintering for various times showing the significant hardness increase and hardness gradient development in the coating system. (a) 1 hour; (b) 11 hours; (c) 120 hours. 


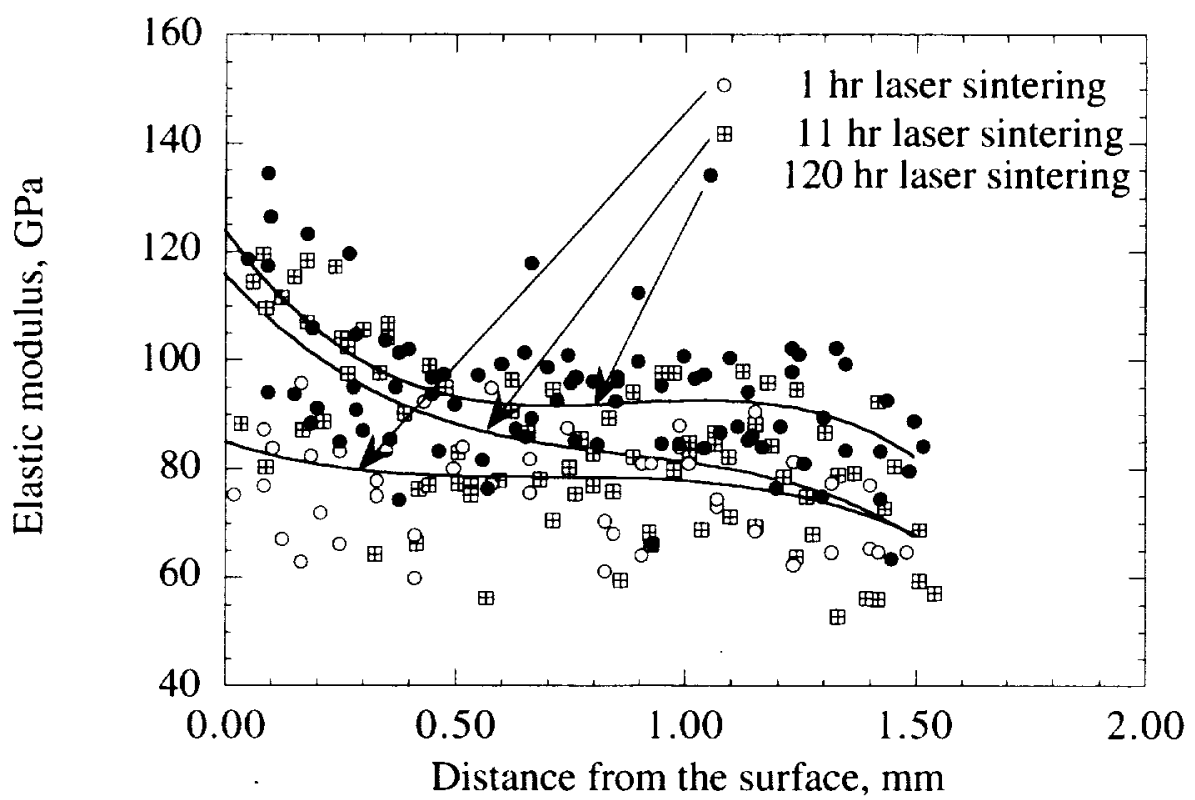

Fig. 9 The elastic modulus distributions in the $\mathrm{ZrO}_{2}-\mathrm{Y}_{2} \mathrm{O}_{3}$ thermal barrier coating as a function of laser sintering time.

Distance from surface, $\mathrm{mm}$
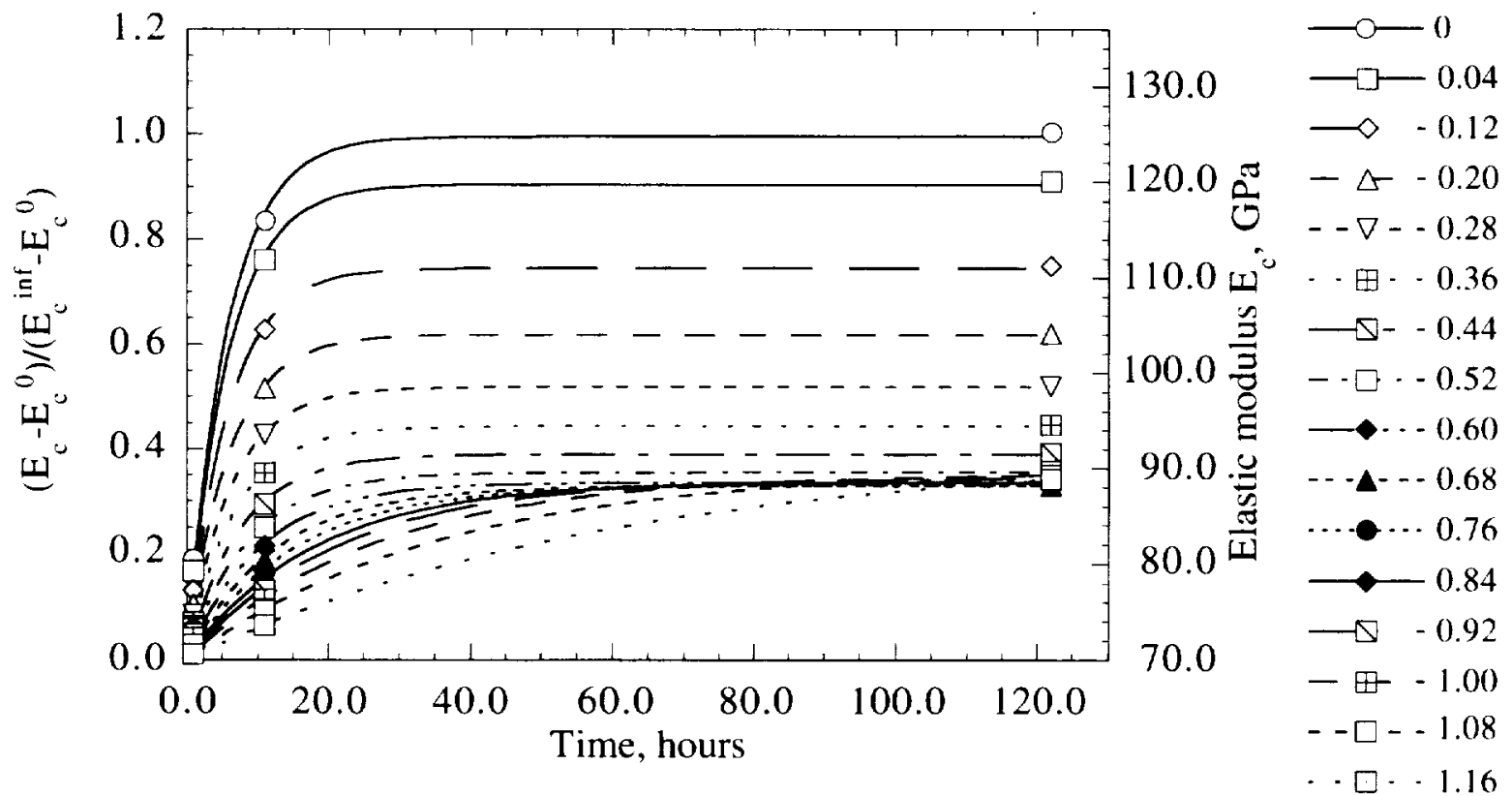

Fig. 10 The experimentally determined modulus change kinetics across the coating system under laser sintering and creep conditions. 


\section{CONCLUDING REMARKS}

High heat flux test approaches have been established to obtain critical properties of thermal barrier coatings under near-realistic temperature and thermal gradients encountered in advanced engine systems. In particular, the laser steady-state technique provides a unique approach for quantitatively monitoring thermal conductivity change kinetics of the ceramic coating under high heat flux conditions. The laser sintering and creep technique offers an effective means for quantitatively evaluating ceramic creep behavior and modulus evolution under simulated engine conditions. The test techniques are important for coating design and development, stress modeling, and life prediction for various thermal barrier coating applications.

A significant thermal conductivity increase was observed during the laser steady-state high heat flux testing. For a $0.25 \mathrm{~mm} \mathrm{ZrO}_{2}-8 \% \mathrm{Y}_{2} \mathrm{O}_{3}$ coating, the overall thermal conductivity increased from the initial value of $1.0 \mathrm{~W} / \mathrm{m}-\mathrm{K}$ to $1.15 \mathrm{~W} / \mathrm{m}-\mathrm{K}, 1.19 \mathrm{~W} / \mathrm{m}-\mathrm{K}$ and $1.5 \mathrm{~W} / \mathrm{m}-\mathrm{K}$ after 30 hour testing at the surface temperatures of $990^{\circ} \mathrm{C}, 1100^{\circ} \mathrm{C}$, and $1320^{\circ} \mathrm{C}$, respectively. The thermal conductivity change kinetics showed the distinguished two-stage rate increase characteristics: a fast and changing rate conductivity increase at the initial "primary" stage, and a slower rate and nearly constant conductivity increase at the "steady-state" stage.

The micro-porosity was observed to decrease with increasing laser testing time during the laser sintering and creep test. The micro-porosity gradients, corresponding to the creep strain gradients across the coating thickness after laser testing, resulted in significant hardness and modulus gradients in the coating. The Knoop hardness values increased from the initial value of 4 $\mathrm{GPa}$ to $5 \mathrm{GPa}$ near the ceramic/bond coat interface, and to $7.5 \mathrm{GPa}$ at the ceramic coating surface after 120 hour testing. During the same period of time, the surface modulus increased from an initial value of about $70 \mathrm{GPa}$ to the final value of $125 \mathrm{GPa}$.

\section{REFERENCES}

[1] CMSX property data, Cannon-Muskegon Corporation, Michigan, 1994.

[2] J. T. DeMasi, K. D. Sheffler, and M. Ortiz, "Thermal Barrier Coating Life Prediction Model Development: Phase I-Final Report," NASA CR-182230, December 1989. 
[3] R. A. Miller and G. W. Leissler, "Characterization and Durability Testing of Plasmasprayed Zirconia-Yttria and Hafnia-Yttria Thermal Barrier Coatings," NASA Technical Paper 3296, March 1993.

[4] D. Zhu and R. A. Miller, "Determination of Thermal Conductivity Change Kinetics under Steady-State Laser Heat Flux Conditions," NASA Technical Memorandum, in press.

[5] C. H. Liebert, "Emittance and Absorptance of NASA Ceramic Thermal Barrier Coating System,” NASA Technical Paper TP-1190, 1978.

[6] C. H. Liebert, "Emittance and Absorptance of the National Aeronautics and Space Administration Ceramic Thermal Barrier Coating," Thin Solid Films, vol. 53, pp. 235-240, 1978.

[7] D. Zhu and R. A. Miller, "Determination of Creep Behavior of Thermal Barrier Coatings Under Laser Imposed Temperature and Stress Gradients," NASA Technical Memorandum 113169, Army Research Laboratory Report ARL-TR-1565, November 1997. Also in Journal of Materials Research, vol. 14, pp. 146-141, 1999.

[8] D. B. Marshall, T. Noma, and A. G. Evans, "A Simple Method for Determining ElasticModulus-to-Hardness Ratios using Knoop Indentation Measurements," Journal of American Ceramic Society, vol. 65, pp. C175-C176, 1982.

[9] S.-H. Leigh, C.-K. Lin, and C. C. Berndt, "Elastic Response of Thermal Spray Deposits under Indentation Tests," Journal of American Ceramic Society, vol. 80, pp. 2093-2099, 1997.

[10] J. P. Singh, M. Sutaria, and M. Ferber, "Use of Indentation Technique to Measure Elastic Modulus of Plasma-Sprayed Zirconia Thermal Barrier Coating," Ceramic Engineering and Science Proceedings, vol. 18, pp. 191-200, 1997.

[11] H. E. Eaton, J. R. Linsey, and R. B. Dinwiddie, "The Effect of Thermal Aging on the Thermal Conductivity of Plasma Sprayed Fully Stabilized Zirconia," presented at Thermal Conductivity, 1994.

[12] R. B. Dinwiddie, S. C. Beecher, W. Porter, D., and A. B. Nagaraj, "The Effect of Thermal Aging on the Thermal Conductivity of Plasma Sprayed and EB-PVD Thermal Barrier Coatings," June 10-13, 1996. 
Public reporting burden for this collection of information is estimated to average 1 hour per response, including the time for reviewing instructions, searching existing data sources, gathering and maintaining the data needed, and completing and reviewing the coliection of information. Send comments regarding this burden estimate of any other aspect of this Davis Highway. Suite 1204, Arlington, VA 22202-4302, and to the Office of Management and Budget, Paperwork Reduction Project (0704-0188). Washington, DC 20503.
1. AGENCY USE ONLY (Leave blank)
2. REPORT DATE
April 1999
3. REPORT TYPE AND DATES COVERED
Technical Memorandum

4. TITLE AND SUBTITLE 5. FUNDING NUMBERS

Thermal Conductivity and Elastic Modulus Evolution of Thermal Barrier Coatings Under High Heat Flux Conditions

6. AUTHOR(S)

Dongming Zhu and Robert A. Miller

7. PERForming ORganization NAME(S) AND AdDRESS(ES)

National Aeronautics and Space Administration

John H. Glenn Research Center at Lewis Field

Cleveland, Ohio 44135-3191

WU $-52.3-21-1.3-00$

9. SPONSORING/MONITORING AGENCY NAME(S) AND ADDRESS(ES)

National Aeronautics and Space Administration

Washington, DC 20546-0001

8. PERFORMING ORGANIZATION REPORT NUMBER

$E-11625$

10. SPONSORING/MONITORING AGENCY REPORT NUMBER

NASA TM $-1999-209069$

11. SUPPLEMENTARY NOTES

Dongming Zhu, Ohio Aerospace Institute, 22800 Cedar Point Road, Cleveland, Ohio 44142; and Robert A. Miller, NASA Glenn Research Center. Responsible person, Dongming Zhu, organization code 5160, (216) $433-5422$.

12a. DISTRIBUTION/AVAILABILITY STATEMENT

12b. DISTRIBUTION CODE

Unclassified - Unlimited

Subject Categories: 24 and 25

Distribution: Nonstandard

This publication is available from the NASA Center for AeroSpace Information. (301) 621-0390.

13. ABSTRACT (Maximum 200 words)

Laser high heat flux test approaches have been established to obtain critical properties of ceramic thermal barrier coatings (TBCs) under near-realistic temperature and thermal gradients that may be encountered in advanced engine systems. Thermal conductivity change kinetics of a thin ceramic coating were continuously monitored in real time at various test temperatures. A significant thermal conductivity increase was observed during the laser simulated engine heat flux tests. For a $0.25 \mathrm{~mm}$ thick $\mathrm{ZrO}_{2}-8 \% \mathrm{Y}_{2} \mathrm{O}_{3}$ coating system, the overall thermal conductivity increased from the initial value of $1.0 \mathrm{~W} / \mathrm{m}-\mathrm{K}$ to $1.15 \mathrm{~W} / \mathrm{m}-\mathrm{K}$, $1.19 \mathrm{~W} / \mathrm{m}-\mathrm{K}$ and $1.5 \mathrm{~W} / \mathrm{m}-\mathrm{K}$ after 30 hour testing at surface temperatures of $990^{\circ} \mathrm{C}, 1100^{\circ} \mathrm{C}$, and $1320^{\circ} \mathrm{C}$, respectively. Hardness and modulus gradients across a $1.5 \mathrm{~mm}$ thick TBC system were also determined as a function of laser testing time using the laser sintering/creep and micro-indentation techniques. The coating Knoop hardness values increased from the initial hardness value of $4 \mathrm{GPa}$ to $5 \mathrm{GPa}$ near the ceramic/bond coat interface, and to $7.5 \mathrm{GPa}$ at the ceramic coating surface after 120 hour testing. The ceramic surface modulus increased from an initial value of about $70 \mathrm{GPa}$ to a final value of $125 \mathrm{GPa}$. The increase in thermal conductivity and the evolution of significant hardness and modulus gradients in the TBC systems are attributed to sintering-induced micro-porosity gradients under the laser-imposed high thermal gradient conditions. The test techniques provide a viable means for obtaining coating data for use in design, development. stress modeling, and life prediction for various thermal barrier coating applications.

14. SUBJECT TERMS

Thermal barrier coating; Laser sintering and creep; Thermal conductivity change kinetics; Elastic modulus evolution

\begin{tabular}{c|c}
\hline $\begin{array}{c}\text { 17. SECURITY CLASSIFICATION } \\
\text { OF REPORT } \\
\text { Unclassified }\end{array}$ & $\begin{array}{c}\text { 18. SECURITY CLASSIFICATION } \\
\text { OF THIS PAGE } \\
\text { Unclassified }\end{array}$ \\
\hline
\end{tabular}

NSN 7540-01-280-5500

19. SECURITY CLASSIFICATION
OF ABSTRACT
Unclassified

Standard Form 298 (Rev. 2-89)

Prescribed by ANSI Std. Z39-18 298-102 
- 